\title{
Unge norske muslimers refleksjoner rundt fenomenet ære
}

\author{
LEVI GEIR EIDHAMAR
}

\begin{abstract}
ENGLISH ABSTRACT: The first part of the article explores how concepts like "honor", "shame" and "guilt" are defined and described within anthropology, sociology and psychology, and highlights discourses within and between these disciplines. The second part is based on qualitative interviews with 24 young Norwegian Muslims. It analyzes their attitudes towards "honor" and "cultures of honor"-as they themselves define these concepts. How do they judge honor according to their own interpretation of Islam? How do they describe and evaluate attitudes and practices in the homeland of their parents? Do they attempt to distinguish between religion and culture in these questions? The majority scorn values and practices in cultures of honor. This is based on religion as well as pure human values. A minority believe honor is an Islamic value that contributes to high moral values.
\end{abstract}

NORSK RESUME: Første del av artikkelen gir en innføring $i$ hoordan begrepene "ære", "skam" og "skyld" blir definert og beskrevet innen sosialantropologi, sosiologi og psykologi. Diskurser innenfor og mellom disiplinene blir belyst. Den andre delen bygger på kvalitative intervjuer med 24 unge norske muslimer. Her analyseres holdningene til det de selv beskrev som ærestenkning. Hvordan bedømmer de denne tenkningen ut fra egen tolkning av islam? Hva tenker de om holdninger og praksis i foreldrenes hjemland? Ønsker de å skille mellom religion og kultur $i$ disse spørsmålene? Flertallet tok skarp avstand til ærestenkning - både på religiøst og allmennmenneskelig grunnlag. Et mindretall mente ærestekning var en islamsk verdi som bidro til høy moral.

KEYWORDS: honor; shame; guilt; islam; young muslims; migrants.

\section{Indledning}

Denne artikkelen analyserer hvordan unge norske muslimer resonnerer rundt ære som begrep og fenomen. Hvordan forstår de begrepet selv? Hvordan vurderer de fenomenet - relatert til islam som religion og foreldrenes kulturelle bakgrunn? Hvilken rolle spiller fenomenet i eget liv? Hvilke forskjeller i syn angående dette 
kan spores mellom den immigrerte foreldregenerasjonen og andregenerasjon med oppvekst i Norge? Artikkelen er skrevet på bakgrunn av litteraturstudier og kvalitative intervjuer med unge norske muslimer.

For forståelse av begrepet "ære", er det viktig å analysere relasjonen til andre begreper i samme familie som "skam" og "skyld". Begrepene blir brukt noe forskjellig innen ulike disipliner. Første del av artikkelen presenterer en gjennomgang av sosialantropologisk, sosiologisk og psykologisk forskningslitteratur som bakgrunn for den andre delens analyse av de kvalitative intervjuene om emnet.

\section{Ære og skam innen sosialantropologisk og sosiologisk forskning}

Innen sosialantropologien rettes fokuset mot institusjonalisert ære og skam. Dette dreier seg ikke om en følelse hos enkeltindividet, men om uskrevne æres- og skamregler med definerte konsekvenser hvis de overholdes eller brytes.

Ruth Benedict ga i 1946 en beskrivelse av det japanske samfunnet som en skamkultur i motsetning til skyld-kulturen i vestlige samfunn (Benedict 1946). En klassiker fra 1966 med artikler av bla John George Peristiany, Pierre Bordieu og Julian Pitt-Rivers beskrev æres- og skamkultur i ulike middelhavsamfunn (Peristiany 1966). Bøkene anga problemstillinger, definisjoner og analyser som senere har preget sosialantropologisk debatt. Etter hvert har flere kritisert bøkene og den etterfølgende forskningstradisjonen for essensialisme, ensidighet og orientalisme (Albera 2006; Baxter 2007, 738-741; de Pina-Cabral 1989; Herzfeld 1980; Herzfeld 2005; Horden \& Purcell 2000; Horden \& Purcell 2006; Noland 2010; Thorbjørnsrud 2002; Thorbjørnsrud 2003; Weidman 2003).

I tråd med middelhavsforskerne beskrev religionssosiologen Peter L. Berger honor som kjennetegn på det førmoderne samfunn og dignity som kjennetegn på det moderne. Mens honor angir identitet ut fra rolle, posisjon og gruppetilhørighet gir dignity identitet til den enkelte som unikt individ i seg selv (Berger et al., 1974, 84). En annen religionssosiolog - Paul Heelas - har beskrevet såkalt "avtradisjonalisering" som en utvikling fra "ytre" til en "indre" moralsk autoritet. Ærestenkning eller honor utgjør da en del av den tradisjonelle "ytre" autoriteten. Hos Heelas dreier dette seg ikke om et kronologisk skifte eller et skille mellom ulike samfunn. Istedenfor virker de to paradigmene parallelt i en pågående prosess hos individer som lever innenfor ulike samfunnstyper (Heelas et al., 1996, 2, 7-8, 212; Lien 2002, 22).

I sitt klassiske verk The Lonely Crowd fra 1950 beskrev sosiologen David Riesman tre typer sosiale karakterer: Den tradisjonsstyrte typen dreier seg i stor grad om motivasjon basert på samfunnsregulert skam. Den indrestyrte typen kan i større grad inkludere skyldmotivasjon regulert ut fra den enkeltes forståelse av sin egen rolle i samfunnet. Den utenfrastyrte typen er motivert ut fra ønsket om å bli positivt evaluert og anerkjent som individ. I likhet med den tradisjonsstyrte typen, dreier dette seg primært om motivasjon ut fra skam, ære og omdømme (Riesman et al., 1950, 336). 
Innen sosialantropologi og sosiologi kan ærestenkning gjerne karakteriseres ved at den enkelte ser seg selv gjennom andres øyne, og lar hensyn til dette bildet være styrende for egen atferd. Atferds-styring ut fra den offentlige mening innebærer tilsvarende mindre vektlegging på frie, personlige, individuelle valg (Bourdieu 1966, 204-211; Guerra et al., 2013, 299; Kirti et al., 2011, 246; Rasmi 2012, 19-20). For eksempel kan innvandrerungdom som er oppvokst i Norge, oppleve at foreldregenerasjonen benytter ærestenkningen som et middel til å oppnå sosial kontroll. Deres individuelle ønsker må underordne seg kollektivet og den enkelte blir motvillig presset til konformitet (Furseth 2008, 156; Nordin 2004).

Hva som gir ære og skam i samfunn kan følge sosiale regler som gir grunnlag for menneskelig samhandling. Dette regelverket er gjerne komplekst og endres over tid. Reglene sanksjoneres gjennom den styrende autoriteten i den andres blikk (Abraham 2000; Bourdieu 1966, 207-211; Gill 2006; Hamady 1960, 34-35, 64; Kirti et al. 2011, 345).

Ære kan både tilskrives individet og kollektivet. Primært dreier kollektivet seg da om familien - ofte den utvidede storfamilien (Baxter 2007, 746-747; Guerra et al. 2013, 299). Ære og skam handler om offentlige rykter - uansett om disse ryktene er sanne eller ikke. Et usant negativt rykte gir like mye skam som et sant. Poenget er altså ikke hva som faktisk har funnet sted, men hva de andre tror har funnet sted. Hvis man ønsker å bevare sitt gode rykte, bør man derfor skjule alle skamfulle handlinger. Innrømmelse fungerer destruktivt - både for en selv og familien (AbuRabia 2011, 34; Baxter 2007, 746, 753; Dodd 1973, 45; Ginat 1982, 177-185; Wikan 2005, 69-70).

Rapporter fra feltarbeid innen tradisjonelle samfunn har knyttet æresbegrepet til kjønn. For mannen kan det dreie seg om positive egenskaper som gjestfrihet, raushet, ordholdenhet og økonomisk vellykkethet. Kvinnen skal være en god mor og pliktoppfyllende husmor. I en del samfunn vil kvinnens ære i stor grad dreie seg om seksualitet. Hun skal være ren - det vil si jomfru - når hun gifter seg. I noen samfunn er det farens, ektemannens og brødres ansvar å passe på at kvinnenes rykte forblir uplettet. Kvinnenes rene seksuelle omdømme er mennenes ære. Hvis mennene selv skulle gjøre seksuelle sidesprang, er det gjerne mindre relevant for deres ære. I muslimske samfunn kan dette gjelde til tross for at normativ islam forskriver like straffer for begge kjønn (Akpinar 2003, 427-430; Baxter 2007, 743,747-752; Casimir \& Jung 2009; Guerraet al.,. 2013, 299-300; Mosquera et al., 2002, 147).

På arabisk skilles det mellom ulike typer ære. Sharaf står for den allmenne æren, mens 'ird betegner familieæren - det vil i praksis si kvinnens seksuelle ære. $A i b=$ "skam" fungerer primært som motpol til sharaf, men er et mer dagligdags og livsnært begrep. I Pakistan benyttes izzat som et samlebegrep om ære (Baxter 2007, 34; Dodd 1973, 44-46; Page \& Yip 2012, 55; Pely 2011, 431; Werbner 2005, 29-30; Wikan 1984, 635-638).

De tradisjonelle samfunn moderniseres. Dette fører til endring - både i ærens funksjon, vektlegging og innhold (Harpel 2010, 5). På 1970-tallet nevnte Peter C. Dodd tre årsaker til endringer i ærestenking innen den daværende arabiske verden: urbanisering, utdannelse og politiske revolusjoner med medførende ideologi- 
endring (Dodd 1973, 46-53). En meget spennende undersøkelse om endring i æresbegrepet har blitt foretatt av Gretty M. Mirdal. Hun dybdeintervjuet de samme dansk-tyrkiske kvinnene i 1980 og 2000. I 1980 var ære og skam sterkt knyttet til seksualitet. De nylig immigrerte mødre ville at døtrene skulle bli minst mulig påvirket av den skambefengte danske kulturen, med sin avkleddhet og frie omgang mellom kjønnene. Tjue år senere var det sosioøkonomisk posisjon og utdannelse som sto i fokus. Da var det skam å snakke dårlig dansk og en ære hvis døtre tok høyere utdannelse på danske universiteter for å bli lege eller ingeniør. Æren var fortsatt viktig, men innholdet i æresbegrepet hadde til dels snudd 180 grader (Mirdal 1984; Mirdal 2006; Mirdal \& Farimagsgade 2000). Spenningen mellom førmodernitet og modernitet er til stede både innenfor mer tradisjonelle samfunn og blant immigranter i vest. Dette gjelder ikke minst æresbegrepet (Abu-Rabia 2011, 37).

I en analyse av endring av religiøsitet hos immigranter som flyttet fra en tyrkisk landsby til Tyskland, pekte sosialantropologen Werner Schiffauer på en bevegelse bort fra kollektiv religionsutøvelse preget av ytre handlinger henimot en indre, individualistisk religiøs overbevisning (Schiffauer 1988). Dette kan tenkes å skje parallelt med at immigrasjonen medfører en endring fra kollektiv basert ærestekning, gjerne basert på ytre forhold, til en mer individualistisk basert dignity-forståelse.

Debatten omkring æresbegrepet innen sosialantropologien er omfattende. Det er et grunnleggende problem at æresforskningen har en tendens til å konstruere en dikotomi med normativ valør. På den ene siden står moderne vestlige samfunn med sin sunne dignity-kultur. På den andre siden står tradisjonelle østlige/sørlige samfunn med sin usunne æreskultur (Ijzerman \& Cohen 2011; Parla 2009). Dette er en forskningsetisk og ideologisk kritikk/selvrefleksjon som bør tas på alvor - noe forskningslitteraturen i økende grad synes å ha gjort. Den tidligere essensialistiske dikotomien mellom skam- og skyld-kulturer er i stor grad forlatt. Den er erstattet av en dikotomi mellom skam- og skyld-fenomenet, der samtlige - både kulturer og enkeltindivider - er preget av begge, men hvor balansen mellom dem varierer og er i kontinuerlig endring (Bertens 2002, 97). Nyere litteratur synes ikke å bekrefte mistanken om vestlige forskeres essenialisering av de "eksotiske andre". Mange av forskerne med de aller klareste æresbeskrivelsene selv har bakgrunn fra, eller røtter i ikke-vestlige samfunn (Abu-Rabia 2011; Akpinar 2003; Al-Krenawi et al., 2001; Ali 2001; Khader 1996; Kirtiet al.,. 2011; Meetoo \& Mirza 2007; Rasmi 2012; Sev'er \& Yurdakul 2001).

Kritikken mot middelhavsforskernes på 60- og 70-tallet dreide seg om generaliseringer og overforenklinger (de Pina-Cabral 1989; Herzfeld 1980; Herzfeld 2005; Horden \& Purcell 2000; Horden \& Purcell 2006; Passaro 1997). For å unngå dette, må æresbeskrivelsene nyanseres. Ideelt bør de reflektere mest mulig av empiriens kompleksitet - der ikke bare hvert samfunn - men også hvert individ, representerer noe unikt.

Muslimers refleksjoner rundt sammenhengen mellom æresbegrepet og islamsk religion er lite behandlet i sosialantropologisk, sosiologisk og religionsvitenskapelig litteratur. Her kan det oppstå spenning mellom religiøse idealer og faktiske gjen- 
nomførte handlinger. I praksis vil enkelte muslimer sette æreskrav over religiøse krav ut fra en tanke om at Gud er størst, men familien og dens ære kommer først.

En del muslimsk forkynnelseslitteratur formaner til å frykte Gud mer enn mennesker - det vil si å ta mer hensyn til Guds dom enn nabolagets sladder. Selv om det å tale nedsettende om andre bryter islamske normer, er dette et forbud mange ikke tar særlig høytidelig (Basri 2010, 2-4; Hamady 1960, 36-37; Khader 1996, 82-90; Mahfuzh 2013, 66-75).

\section{Ære, skam og skyld innen psykologisk forskning}

Den psykologiske forskningen på de aktuelle emosjonelle fenomenene har vært særlig omfattende de siste 40 årene. Her skal det kort pekes på noen viktige aspekter.

Helen Block Lewis sto for et forskningsmessig gjennombrudd på området. Hun anså dikotomien "skyld kontra skam" som mer fruktbar enn "ære kontra skam" som redskap i analyse av pasientsamtaler. På bakgrunn av egen empiri fant Lewis det hensiktsmessig å konstruere en definisjon av skyld som selvets dom over egne handlinger, mens skam og ære ble definert som andres dom over egen personlighet, slik denne dommen fremstår i individets bevissthet (Lewis 1971, 251-256). Lewis stod sentralt $i$ et internasjonalt forskningsvettverk rundt emnet. Hun ga støtet til en omfattende empirisk forsking knyttet til det såkalte TOSCA-programmet (Test of Self Conscious Affections). Selv om TOSCA-forståelsen av begreper som ære, skam og skyld er gjenstand for grundig debatt, er den absolutt dominerende innen dagens psykologiske forskning (Cohen et al., 2012; Joireman 2004, 229; Luyten et al., 2002). Noen av de sentrale komponenter i TOSCA-definisjonene av ære, skam og skyld skal her kort presenteres.

Æres- og skamfølelsen er motivert ut fra hensynet til eget omdømme, mens skyldfølelse er motivert av empati for andre. Det betyr at æres- og skamfølelsene er selv-orienterte, mens skyldfølelsen er andre-orientert (Baumeister et al., 1995, 259261; Hoffman 2000, 114-117; Joireman 2004, 234; Kaufman 1996, 42; Silfver \& Helkama 2007, 244; Tangney \& Dearing 2002, 81-86; Tangney et al., 2011, 713-714; Zahn-Waxler \& Robinson 1995, 152-154).

Ære og stolthet dreier seg om å bli sett og positivt vurdert av de andre. Skam den motsatte følelsen innenfor omdømmedimensjonen - fører dermed logisk til et ønske om å benekte, skjule seg og eventuelt slå tilbake. Den empatimotiverte skyldfølelsens reaksjon på egen handling står også i motsetning til skammens - men da innen en annen dimensjon enn ærens: et ønske om å erkjenne, bekjenne og gjøre opp (Ketelaar \& Tung Au 2003; Lewis 1971, 504; Lutwak et al., 2001; MacDonald 1998, 141-142; Scheff 1988, 400-401; Scheff 1995, 393-394; Tangney \& Dearing 2002, 18-21, 49; Tangneyet al.,. 2011, 713; Wurmster 1987, 67).

Æres- og skamfølelse på den ene siden, og skyldfølelse på den andre, korrelerer gjensidig negativt. Det vil si at de to måtene å føle og tenke på fortrenger hverandre. Omdømmemotivert ære og skam-tekning er fokusert på den andres bedømmelse av en selv. Empatimotivert skyld-tenkning er fokusert på konsekvensen for den andre. 
De helt motsatte fokuspunktene er gjensidig konkurrerende (Barrett 1995, 46; Fischer \& Tangney 1995; Joireman 2004, 230; Tangney \& Dearing 2002, 28, 81-82; Tangney et al., 1996; Tangney et al., 2007).

På bakgrunn av det som er sagt ovenfor, har jeg for egen regning valgt å konstruere to definitoriske teser som beskriver de to dimensjonenes etiske virkemåte. Dette som en forlengelse av TOSCA-definisjonene:

- Omdømmemotivert æres- og skamfølelse ser seg selv gjennom den andres øyne i den hensikt å fremstå mest mulig positivt selv.

- En empatimotivert skyldfølelse ser sine egne handlinger overfor den andre gjennom den andres øyne og erkjenner med beklagelse at handlingene innebærer negative konsekvenser for den andre.

Forståelsen av begreper som ære og skam er åpenbart forskjellig de to disiplinene psykologi og sosialantropologi imellom. Slik bør det også være. Psykologien har som målsetting å beskrive det allmennmenneskelige på tvers av kulturforskjeller, mens sosialantropologien retter fokus mot det særegne for det enkelte samfunn til forskjell fra andre. Prinsipielt sett er likevel den definisjonsteoretiske forskjellen viktigst. Sosialantropologien beskriver fenomener gjennom begrepene slik de faktisk brukes på ulike språk. Dette dreier seg om lingvistiske definisjoner som bedømmes ut fra sannhetskriterier. Innen fagpsykologien benyttes vitenskapelige definisjoner som bevisst er konstruert for et bestemt formål. De bedømmes ut fra hensiktsmessighetskriterier (Adamska-Salaciak; Alshawi 1987; Gerring 1999; Pap 1964; Rey 2000; Robinson 1972).

Dette kan for eksempel dreie seg om hva et fenomen som "ære" egentlig er. “Ære" er ikke en a priori gitt empirisk størrelse som vitenskapen skal forsøke å oppdage og beskrive. Istedenfor er det et rent konstruert begrep, laget for å beskrive noe som finnes empirisk. Lingvistiske definisjoner som benyttes innen sosialantropologien, beskriver hvordan allerede konstruerte begreper brukes innen ulike språk. De konstruerte definisjoner som benyttes innen psykologien, er derimot bevist nylagede.

Til tross for forskjeller i metode, empirisk materiale, fokus og bedømmelseskriterier, finnes enkelte fellestrekk i beskrivelsen de to disiplinene imellom. I all hovedsak gir de en negativ vurdering av omdømmemotivert ærestenkning ut fra kriterier knyttet til samfunnsfunksjonalitet og psykisk helse.

Den følgende analysen har sitt primærfokus på ære i sosialantropologisk forstand, mens det psykologiske skillet mellom skamfølelse og skyldfølelse blir sporadisk berørt. Imidlertid er bevissthet om begge innfallsvinklene nyttig for analysen av synspunktene.

\section{Ære og skam blant unge norske muslimer}

Den empiriske delen av denne artikkelen bygger på kvalitative intervjuer med 24 respondenter i aldersgruppen 18-32 år som ble gjennomført i perioden 2005-2012. Om lag halvdelen hadde vokst opp i Norge, mens de andre hadde ankommet landet 
som unge eller unge voksne. Til sammen hadde respondentene røtter fra 11 forskjellige land. På intervjutidspunktet var alle bosatte på Øst- og Sørlandet. Utvalget ble foretatt ut fra ønske om maksimal variasjon innen rammen av relevante respondenter (Repstad 2007, 57-60). Respondentene ble rekruttert ved en kombinasjon av ulike metoder. Noen ble kontaktet gjennom moskéer og muslimske organisasjoner, mens andre ble mer tilfeldig kontaktet på T-bane, arbeidsplasser og lignende. I tillegg benyttet jeg mitt eget muslimsk kontaktnett. Dette ble så kombinert med snøballmetoden.

En sentral problemstilling i intervjuene dreide seg om hvorvidt tradisjonell muslimsk æresforståelse kan sies å være i overenstemmelse med islam som religion. Denne problemstillingen er lite behandlet - både innen forskningen og i normativ muslimsk litteratur. Spørsmålet syntes å være viktig for de fleste av respondentene og vakte sterkt engasjement. Svarene gikk i flere ulike og til dels motstridende retninger.

På tross av rik variasjon var to fellestrekk tydelige. Samtlige respondenter viste et stort engasjement og var mer reflekterte angående emnet enn man kunne forvente fra gjennomsnittet av ikke-muslimske nordmenn. Samtidig ga alle mer eller mindre klart utrykk for at ærestenkning var en viktig del av foreldrenes kulturelle bakgrunn og tradisjonell muslimsk kultur. Enkelte mente at dette kunne ha endret seg noe i perioden siden foreldrene emigrerte til Norge. I dette spørsmålet hadde de oppfatninger som samstemte med hovedtrekkene i den ovennevnte sosialantropologiske beskrivelsen. De fleste ga likevel en æresbeskrivelse som faglig sett kan karakteriseres som essensialistisk.

Variasjonen i synspunkter fordelte seg i hovedsak langs to akser. For det første var noen kritiske til ærestenkning, mens andre mente den hadde en positiv funksjon. For det andre var noen opptatte av å skille religion og kultur i dette spørsmålet, mens andre mente islamsk religion og muslimsk kultur/muslimske samfunn i hovedsak sto for det samme og ikke kunne skilles. Variasjonene på de to områdene kan teoretisk tenkes fordelt lineært langs hver sin akse. Fordelingen er innbyrdes uavhengig. De to variablene utgjør dermed separate dimensjoner innenfor en todimensjonal typologi. En slik typologi kan skisseres ved et firefelt som angir i hvilken grad respondentene er for eller imot ærestenkningen innen henholdsvis islamsk religion og muslimske samfunn: 


\begin{tabular}{|l|l|l|}
\hline & $\begin{array}{l}\text { Det er stor forskjell i synet på ære mellom } \\
\text { islamsk religion og muslimsk kultur. De } \\
\text { to størrelsene må skilles. }\end{array}$ & $\begin{array}{l}\text { Det er liten forskjell i synet på ære } \\
\text { mellom islamsk religion og muslimsk } \\
\text { kultur. De to størrelsene er vanskelig } \\
\text { å skille. }\end{array}$ \\
\hline $\begin{array}{l}\text { Negativ hold- } \\
\text { ning til ære- } \\
\text { stenkning }\end{array}$ & $\begin{array}{l}\text { A) For: Islamsk religions anti- } \\
\text { ærestenkning } \\
\text { Mot: Muslimske samfunns ærestenk- } \\
\text { ning }\end{array}$ & $\begin{array}{l}\text { B) Mot: Ærestenkningen innen } \\
\text { islamsk religion og muslimske } \\
\text { samfunn }\end{array}$ \\
\hline $\begin{array}{l}\text { Positiv hold- } \\
\text { ning til ære- } \\
\text { stenkning }\end{array}$ & $\begin{array}{l}\text { C) } \text { For: Islamsk religions konstruktive } \\
\text { ærestenkning } \\
\text { Mot: Muslimske samfunns destruktive } \\
\text { ærestenkning }\end{array}$ & $\begin{array}{l}\text { D) For: Ærestenkningen innen } \\
\text { islamsk religion og muslimske } \\
\text { samfunn }\end{array}$ \\
\hline
\end{tabular}

A. Man oppfatter at tradisjonell muslimsk kultur har en sterk vektlegging på æresbegrepet - noe man tar avstand fra. I stedet ønsker man å følge religionen islam som tolkes slik at menneskelig ære bør spille en underordnet rolle

B. Man oppfatter at både religionen islam og tradisjonell muslimsk kultur har en vektlegging av ære - noe man selv tar avstand fra

C. Man oppfatter at tradisjonell muslimsk kultur har en måte å praktisere ære på som man tar avstand fra. Man ønsker isteden å følge religionen islam som i motsetning til muslimsk kultur, oppfattes å ha en konstruktiv æresforståelse

D. Man oppfatter at religionen islam har en konstruktiv æresforståelse som i hovedsak blir fulgt opp i muslimske samfunn. Dette ønsker man å støtte.

Typologien er konstruert i analysefasen i etterkant av intervjuene. Den er sprunget ut av materialet ved å benytte metoder beskrevet innenfor Costructivist Grounded Therory og Informed Grounded Theory (Bryant \& Charmaz 2007; Charmaz 2003; Charmaz 2006; Mills 2006; Mills et al., 2008; Riessman 2009; Thornberg 2012; Thornberg \& Charmaz 2013).

A: Skyldtenkning innen islamsk religion er konstruktiv, mens skamtenkningen innen mange muslimske kulturer er destruktiv.

Denne måten å tenke på hadde oppslutning fra et stort flertall av respondentene.

Noen av dem viste et tydelig emosjonelt engasjement i forhold til dette. Aima, en 22 år gammel medisinerstudent med pakistansk bakgrunn tok sterk avstand fra izzatbegrepet (punjabi: “ære") slik hun mente det ble forstått og praktisert innen tradisjonelle muslimske samfunn:

Jeg: Hvordan ser du på izzat?

Respondent: Det er et kjempeproblem. Man har denne kulturelle eller familiære æren (...) denne æregreia og hva folk vil si - det er et så overordnet mål i livet deres at det er nesten provoserende. (...) Altså: jeg ser på det som en religion for enkelte - den derre æresproblematikken - for de er så rusa inn i det at det går over alle grenser. Helt klart provoserende for meg og også imot religionen. (...) Det med det statusorienterte materialistiske livet (...) har ikke noe grobunn i islam i det hele tatt. Det er deg og 
Gud. (...) Det er Ham du skal svare til når det gjelder handlinger. Det er ikke folk du skal vise rundt. Det er overfor Ham du skal leve et godt liv og det er overfor Ham du skal svare for dine handlinger. Det er der den store æren ligger. Hva er vitsen med å ha ære, når du ikke har ære overfor Gud? Det er tankegangen min, men det er et kjempeproblem, blant annet i den pakistanske kulturen. (...)

Jeg: Og det mener du er veldig utbredt?

Respondent: Det er veldig utbredt - i hvert fall i foreldregenerasjonen. En 22-åring i Pakistan ville ha en helt annen formening enn meg (...).

Jeg: Du virker veldig engasjert?

Respondent: Ja veldig! Det provoserer meg nesten. Det er så uislamsk. Det er vanskelig for de norske å forstå at det er et så drastisk skille mellom religion og kultur (Aima, 22, pakistansk bakgrunn).

Aima tok utgangspunkt i egne opplevelser i det pakistanske miljøet i Norge. Der opplevde hun at fokuseringen på izzat virket styrende på en negativ måte. Blant annet gjaldt dette valg av ektefelle. Hovedpoenget for henne var at den æresfokuseringen hun mente å finne i tradisjonelle muslimske samfunn bryter grunnelegende med religionen islam. Rykter, hva folk snakker om og hvilken status man har, burde ikke bety noe som helst for en sann muslim. Det eneste som er viktig, er Guds dom. Man skal frykte Gud - ikke mennesker. Menneskenes dom betyr intet - Guds dom betyr alt. Ut fra Aimas oppfatning er tradisjonell muslimsk kultur på direkte kollisjonskurs med islamsk religion i dette spørsmålet.

Lignende synspunkter kom fra et flertall av respondentene. Deres oppfatning av hva som er sann og egentlig islam ble kontrastert til kulturelt nedarvede tradisjoner og uvitenhet. To av dem uttrykte det slik:

Ære og skam kommer fra kulturen og gamle tradisjoner og gammel bondsk tankegang hos analfabeter fra 70-tallet fra bondelandet i Pakistan som har kommet ned hit, og som ikke har utviklet seg og holder på gamle tradisjoner. De vet ikke så mye om islam. (...) De holder bare på gamle tradisjoner de har lært av forfedrene sine som ikke har noe med islam å gjøre (Jasmin, 26, pakistansk bakgrunn).

Det (ære) er kulturelt begrep. Det har ikke direkte med islam å gjøre. (...) Jeg tar veldig avstand fra dette. Jeg ønsker å følge islam (Omar, 25, pakistansk bakgrunn).

Flere ga uttrykk for det prinsipielle i motsetningen mellom Guds og menneskers dom:

Man skal ikke bry seg om hva andre mener. Det er kun Gud som kan dømme deg. Ære er alt. Men ut fra islam er dette feil. (...) Man skal bry seg om hva Gud tenker, og ikke hva mennesker tenker (Ibrahim, 28, irakisk bakgrunn).

Det er ikke hva andre mener om deg som er fokusen. Fokusen er hvordan du er, hvordan du behandler andre, om du tror på Gud (Amina, 23, pakistansk bakgrunn).

På samme måte som innen TOSCA-forskningen, ble det her stilt opp en motsetning mellom omdømmebasert ære og skam på den ene siden og skyld på den andre. Og $\mathrm{i}$ likhet med TOSCA var det skylden som ble positivt vurdert. Men til forskjell fra denne psykologiske tradisjonen, ble det innført en annen dikotomi som absolutt 
overordnet - dikotomien mellom menneske og Gud. Ære og skam gjelder relasjonen til andre mennesker, mens skyld er noe man primært har overfor Gud. Den ovennevnte gruppen av respondenter anså islam for å være en religion med fokus på skyldforholdet til Gud og ikke æresforholdet til mennesker. For å si det enkelt og populært: Guds dom er viktigere enn naboenes sladder.

Disse respondentenes "evighetsmotiverte skyld-tenkning i forhold til Gud" brøt dermed både med en "omdømmemotivert æres- og skam-tenking i forhold til mennesker" beskrevet i sosialantropologien og den mer sekulære "empatimotiverte skyld-tenkningen i forhold til medmennesker" beskrevet i den psykologiske TOSCA-forskningen.

Denne gruppen resonerte med sterkt engasjement i henhold til type A i den ovennevnte typologien. Dette resonnementet forutsatte et skarpt skille mellom religion og kultur. Sosialantropologisk kan det innvendes at de to størrelsene er så sammenvevde begreper at de vanskelig lar seg skille (Krogseth 2009). Det respondentene syntes å forsvare var et skille mellom islam som normativ religion bygd på de åpenbarte hellige skrifter, på den ene siden - kontra en etnisk kultur hvor man i generasjoner har tolket islam ut fra manglende kjennskap til de hellige skriftene, på den andre. Respondentene foretok selvfølgelig ingen sosialantropologisk analyse, men brukte skillet strategisk i sitt forsvar for det jeg her benevner som type A.

\section{B: Både religionen islam og muslimske kulturer står for en destruktiv forståelse av ære}

I mitt materiale var det bare én respondent som kunne sies å representere denne typen tenkning. Det var 21 år gamle Abdi med somalisk bakgrunn som hele sitt liv hadde bodd i Norge. Han mente ære og skam var viktig i Koranen og dermed i islam som religion. På dette området skilte han ikke mellom religion og kultur:

Alle i det muslimske miljøet skal vite hvem som er best til å opprettholde religionen og hvem som er de dårligste. Hvordan du blir rangert på den listen, går ryktet ditt ut fra. (...) Hovedbudskapet i Koranen går mer ut på at du ikke skal bringe skam over familien. Du skal alltid være perfekt - hvis ikke, fører du skam over deg selv. (...) Ryktet er viktig. Du skal kunne være en såpass god person at du ikke bringer skam over deg og din familie. Det er det viktigste både i Koranen og kulturen. Det er ganske innvevd.

Dette var en tankegang Abdi selv ønsket å ta avstand fra:

Jeg har sagt til mamma at hun fokuserer alt for mye om hva andre måtte tenke og mene om henne. Jeg kommer til å bruke resten av mitt liv på ikke å bry meg om hva folk mener om meg, så lenge jeg selv mener det (jeg gjør) er riktig. Da trenger man ikke tenke på omdømme og skamfølelsen. Det eneste jeg vil tenke da er empati med andre mennesker. (...) Jeg er ikke uenig med Koranen i sin helhet. Men jeg er uenig i den uskrevne regel om at man ikke skal bringe skam over deg selv og familien (Abdi, 21, somalisk bakgrunn).

På spørsmål om "uskreven regel" betydde at dette faktisk ikke stod skrevet i Koranen, ble Abdi usikker. Dette ville han ville gå hjem og undersøke. Han ønsket å ha empati som rettesnor for sin personlige moral. I den grad Koranen eller islam eventuelt skulle bryte med dette, mente han det var riktig ikke å la seg styre av det. Ho- 
vedmotivasjonen for å ta avstand fra det han anså som muslimsk æresforståelse, var her ikke en islamsk tanke på Gud som dommer som innen type A, men en allmennetisk tanke om medmenneskelig empati som overordnet etisk verdi. Dette samstemmer med TOSCA-inspirerte idealer om empati som en psykososial sunn motivasjon for handling.

Begge de æreskritiske typene A og B representerer avtradisjonalisering. Innen type A oppgis religionen som begrunnelse for denne endringen. Dette dreier seg om en islam-forståelse som $i$ et utefra-perspektiv i seg selv kan sies å være preget av avtradisjonalisering og vestlig tankegang. Innen type B er det kun en immanent forståelse av menneskets verdighet som legges til grunn for en klar dignity-tekning (Heelas, Lash \& Morris 1996, 2, 7-8, 212).

\section{C: Tradisjonell muslimsk kultur står for en destruktiv æresforståelse, mens religionen islam vektlegger ære på en konstruktiv måte}

Adam med bakgrunn fra Bosnia var den eneste respondenten som resonnerte i henhold til en slik type tenkning. Han hadde kommet til Norge i ung alder og ga uttrykk for stor religiøs bevissthet. Det viktigste i livet hans var å følge sharia. Han var til kritisk til æresforestillinger i hjemlandet, som han mente mer var knyttet til kultur og tradisjon enn religion. For ham var ære det å praktisere islam og å følge i profetens fotspor. Han mente absolutt Guds dom er viktigere enn menneskenes dom. Samtidig nyanserte han dette med at menneskers viten om en handling og deres evaluering ikke er uten betydning innen sharia. Dette knyttet han til en fortelling om profeten Muhammad som var ute sammen med en av konene sine. Da noen muslimer kom forbi, var det viktig for profeten å poengtere at denne kvinnen var konen hans. Han ville ikke de skulle tro at han var ute med en annen kvinne. Adam mente dette viste at profeten var redd for hva disse muslimene måtte tenke og hvilke rykter de ville spre.

Adam: I islam skal man ta vare på ens ære og verdighet, så man bør bli bekymret for at folk har fått vite noe om deg som kan være negativt. Har noen sett meg med en kvinne som ikke er min kone, så bør jeg bli bekymra for at (...) de sier det til andre - og da vil ryktet spre seg i samfunnet. Og det er en positiv frykt.

Jeg: Vil du da si at det er verre at du var sammen med denne kvinnen og jeg så det, enn at ingen så det?

Adam: Det er verre at du har sett det. For Gud vet alt og Gud tilgir i større grad enn mennesker tilgir. Og her kommer et interessant aspekt: Har du gjort en handling som er imot sharia - for eksempel hatt sex utenfor ekteskap - og bare Gud vet om det, så holder det for deg å be Gud om tilgivelse. (...) Det var en kvinne på profetens tid som hadde begått utukt. Hun kom til profeten og sa det. Han snudde seg vekk - han ville ikke høre på det. Hun kom flere ganger og sa det samme. Så til slutt sa profeten (s.a.w.) "Er det noe galt med denne damen?" For hun ville renvaske seg ved å si at hun hadde gjort en synd. Og til slutt så ble hun drept - steinet. Fordi hun ville bli ren overfor Gud her, så hun slapp å svare for Gud på dommens dag. Hadde hun ikke sagt noe, hadde Gud kanskje tilgitt henne.

Jeg: Var det positivt at hun sa det, eller ikke? 
Adam: Det var ikke positivt. For hun kunne bli tilgitt ved å be om tilgivelse. Og levd et godt liv her.

Jeg: Så det var ikke sånn at hun sonet sin synd ved å ofre livet?

Adam: Jo, definitivt. Men det var ikke nødvendig å gå til så drastiske tiltak. Noen følgesvenner begynte å snakke om denne kvinnen. Så sa profeten: “Hun er blitt tilgitt og hun er i paradiset" (...) Men hun kunne også ha beholdt livet og bedt om tilgivelse og blitt fri. For Gud tilgir alle synder unntatt shirk. (Adam, 26, bosnisk bakgrunn).

Adam mente man skulle bekjenne sine synder for Gud i enerom for at Gud skal kunne tilgi. Samtidig anså han det som etisk riktig å skjule sine synder for andre mennesker. Det bør gjøres av to grunner. For det første vil det å bekjenne synder for mennesker føre til at man som etisk forbilde bidrar til en legitimering av de aktuelle syndene. For det andre fører det til en helt unødvendig bruk av sharia-straffene. Dersom en handling ikke er bevitnet av mennesker, er sharia-straffen uaktuell. Her skilte han mellom Guds dom i evigheten - hvor tilgivelse spiller en sterk rolle - og en sharia-dom her på jorden som er avhengig av menneskelige vitner - og hvor tilgivelse ikke er aktuelt på samme måte. Dersom en synd er skjult, fører den ikke til skam og ødelagt rykte. På tross av eventuelle skjulte synder under ærens overflate, bidrar et sharia-basert æresbegrep likevel til mindre legitimering av synd.

Adam ble presentert for en case om hvorvidt en muslimsk gutt som har tagget på skolen, burde innrømme det for læreren. I motsetning til seksuelle synder, er dette en forgåelse som ikke er omtalt i sharia-tradisjonen. Svaret innledet en samtale om avveining mellom to onder: På den ene siden en innrømmelse som fører til skam og legitimering av synd - på den annen side en fornektelse som innebærer løgn.

Adam: Hvis læreren spør generelt i klassen om det er noen som har tagget, så er jeg usikker (...) Men hvis han hadde blitt spurt personlig: "Ahmed, har du tagget?", så tror jeg nok han måtte ha sagt det, så han unngikk å lyve. (...). Når det gjelder kulturen, tror jeg folk skjuler en del ting og lyver om en del ting bare for å bevare æren. (...) Hvis du skal følge religionen, bør du alltid snakke sant, man praksisen i en (muslimsk) kultur er gjerne den stikk motsatte.

Jeg: Finnes det enkelte tilfeller hvor det islamsk sett kan forsvares å lyve for å beskytte sin ære?

Adam:(Pause) Det er kanskje lettere å lyve og så å søke tilgivelse fra Gud og gjøre en oppriktig anger og ikke gjenta det - enn å si sannheten der og da og bli utsatt for de konsekvensene som måtte komme.

Jeg: Mener du det forsvares ut fra islam?

Adam: Det vet jeg ikke - det er jeg veldig usikker på. (...) Det er noe i islam som sier at å snakke om en synd, er synd i seg selv. Allah er den som skjuler vår synd. Han skjuler våre synder for hverandre. Når du forteller om noe Allah har skjult, er det en synd i seg selv. Så det er ikke bra i det hele tatt å komme fram med det, hvis du har gjort noe galt.

Både løgn og avsløring av egne synder for andre mennesker ble ansett som brudd på religiøse verdier. Forskjellen var at innrømmelse av skyld i større grad fikk nega- 
tive konsekvenser i livet på jorden. Samtidig kritiserte Adam muslimske samfunn for ukritisk å bruke løgn for å beskytte æren.

Adams synspunkter kan oppsummeres med at frykten for syndens medfølgende skam virker preventivt og at den dermed er konstruktiv. Selv om han til dels hadde en negativ evaluering av skyld- og skam-tenkningen slik det tradisjonelt fungerer, hadde han en nyansert positiv evaluering av ære og skam knyttet til overholdelse av sharias leveregler.

\section{D: Både religionen islam og mange muslimske kulturer har en konstruktiv æresforståelse}

I mitt materiale var det fire respondenter som i større eller mindre grad forsvarte deler av tradisjonell æresforståelse. Den som klarest ga uttrykk for denne type tenkning, var 18 år gamle Zahra - en shiamuslimsk kvinne med irakisk bakgrunn som kom til Norge i barneårene. Ifølge henne var den tradisjonelle muslimske æresforståelsen nesten fullstendig i overensstemmelse med islam som religion. Hun beskrev det arabiske begrepet sharaf som mer omfattende enn det norske ordet ære. Sharaf omfattet både handlingene i seg selv og ryktet som oppstod som en naturlig konsekvens av handlingene. Hun anså det som et moralsk begrep og mente bevissthet om sharaf bidrar til å høyne moralen hos den enkelte: "Sharaf på arabisk betyr at du har god ære. Altså, du er ærlig, du gjør ikke noe feil - og så videre." Sharaf og det å ha et godt rykte ble tilskrevet en sentral og selvfølgelig plass i islam som religion: "I Koranen og blant muslimske familier så er ryktet det som har mest å si." Hun mente de tradisjonelle muslimske samfunnene - i motsetning til det norske står nær religionen islam i synet på æresbegrepet:

I den norske kulturen føler jeg at ære ikke betyr like mye som i islam og den arabiske kulturen. Ordet sharaf i den muslimske kulturen betyr hele livet. Har en person dårlig sharaf, er den personen ferdig. Det er ikke noe vits (Zahra, 18, shiamuslim med irakisk bakgrunn).

Zahra utrykte eksplisitt at det ikke var noen vesensforskjell på muslimsk kultur og islamsk religion i dette spørsmålet. En persons rykte var noe man i hovedsak har ansvar for selv - det var selvforskyldt og dermed fortjent:

Du får et godt rykte om du er en god person. (...) Det er du som lager rykte til deg selv. Om du oppfører deg idiotisk, får du selvfølgelig dårlig rykte. Om du holder deg til det du får lov til, så får du godt rykte. (...) Veldig mange her (i Norge) blir jo dårlige jenter og går ut av islam, og da får du selvfølgelig dårlig rykte. Men om du holder deg innenfor det islam sier og hvordan du har blitt oppdratt, så får du et godt rykte.

Zahra ga en beskrivelse av tradisjonell arabisk æresforståelse, der gjenopprettelse av tapt sharaf var viktig. Dette var noe hun selv delvis sluttet seg til, men visse former tok hun klart avstand fra:

Zahra: I den arabiske kulturen betyr sharaf veldig mye - så om noen tråkker på din sharaf, skal du ikke godta det. Da skal du ikke holde munn. Du skal prøve å forsvare din sharaf og vise hva den er god for. (...) Man skal prøve å få sharaf'en sin tilbake.

Jeg: Hvordan gjør man det? 
Zahra: Noen truer, noen slår, mens andre bare beviser det motsatte av det som har blitt sagt igjennom handling.

Jeg: Så du kan gjøre det igjennom hevn, men også bare ved å bevise at det er annerledes?

Zahra: Ja.

Jeg: Men, hevn kan også være en måte å få tilbake sharaf på?

Zahra: Ja - eller det kommer an på hva slags hevn. Selvfølgelig skal du ikke drepe for å få din sharaf tilbake. Selv om det er mange som tolker ordet sharaf feil. Si at en jente blir voldtatt. Da skal brødrene ta sharaf'en tilbake. I gamle dager gikk de gjerne og drepte den personen for å få blodet tilbake. (...) Som sagt, ordet sharaf blir tolket på en veldig feil måte. Noen foreldre dreper datteren sin om hun har hatt sex før ekteskap. Og når de dreper den jenta eller gutten, så får de sharaf'en tilbake - og det er jo helt feil.

Zahra ga en positiv og ideell beskrivelse av sharaf-begrepet som hun knyttet til islam som normativ religion. Hvis noen i tradisjonelle arabiske samfunn dreper for å gjenopprette sharaf, er det fordi de har en feil tolkning av begrepet. På den andre siden understreket hun at det kunne oppstå falske rykter, det vil si rykter som ikke stemmer med virkeligheten:

De får et dårlig rykte på tross av at de er gode personer. På arabisk heter det madelon, falsk beskyldning. Og det kan ryktet også være påvirket av. (...) Uansett er det veldig mye sjalusi, og da ødelegger man andres rykte.

Dette var noe hun hadde opplevd selv:

Folk snakker og snakker og snakker - uansett om du er en dårlig person eller en bra person. Så lenge du har troen på deg selv, kan folk bare snakke. (...) Jeg har gått igjennom veldig mye. Folk har baksnakket meg. Men jeg har lært med tiden at folk snakker - uansett om du er god eller dårlig. Så lenge du har troen på Allah, så lenge du har troen på deg selv, så betyr det ingenting.

Slike falske rykter vil en dag bli avslørt. Rykter er viktige i livet her på jorden, men på dommens dag er Gud alene dommer og han alenen kjenner den fulle sannheten:

Zahra: Falske ryker er falske rykter uansett. Det kommer uansett en dag der - om du lyver for eksempel og sier at hun er en dårlig jente, mens hun er en bra jente - så kommer det en dag da alle vet at hun er en bra jente. Det er ingenting som blir skjult.

Jeg: Så falske rykter kan være et problem her, men ikke på dommedag?

Zahra: Ja, Allah ser jo alt vi gjør. Men her på jorda er det jo mange slemme som vil ødelegge andres rykte. (...) det er bare Gud som vet hva du har gjort. Det er Gud som ser hva du gjør. Gud skal ikke høre det fra andre. Det er kun Gud som ser hvem du er.

Zahras beskrivelsen av dårlig sharaf samsvarte i høy grad med TOSCA-forståelsens tese om at skammen ikke skiller mellom person og handling og at en negativ handling gir hele mennesket et negativt stempel: "Har en person dårlig sharaf, er den personen ferdig. Det er ikke noe vits. (...) En jente uten ære er ikke verdt noe." Hun sto for oppfatninger preget av kollektiv tenkning, noe som stemmer med bildet teg- 
net en del sosialantropologer: “Jeg ser på meg og familien som én person. De som snakker om meg, snakker om familien min og de som snakker om familien min, snakker om meg."

Zahras synspunkter kan oppsummeres slik: De som gjør det som er rett, fortjener ære og et godt rykte, mens de som bryter Guds bud, fortjener vanære og et dårlig rykte. Denne æresforståelsen samsvarer både med islamsk religion og tradisjonell muslimsk kultur. Dette gjelder imidlertid bare de sanne ryktene. Falske rykter skal man derimot tilbakevise og heve seg over. Dette kan gjøres på ulikt vis - men hvis noen i muslimske samfunn dreper for å gjenopprette æren, så bunner det i en misforståelse av det islamske æresbegrepet. Guds dom på dommedag handler ikke om ære eller rykte, men baseres kun på den fulle sannhet om våre liv som Gud alene kjenner.

\section{Ærens innhold: Seksualitet og kjønn}

Til forskjell fra beskrivelsene i en del sosialantropologisk litteratur, var gjestfrihet, gjenytelse og gjengjeldelse ikke nevnt som noe man tilskrev tradisjonell æresforståelse. Én av flere årsaker kan være at flertallet var svært negative til æresbegrepet. Dermed ville de ikke knytte det til et positivt fenomen som gjestfrihet. Dessuten kan gjengjeldelse faktisk være lite vanlig i muslimske miljøer i Norge - til forskjell fra litteraturens beskrivelser fra enkelte tradisjonelle samfunn.

Når det gjaldt forståelsen av hva ære dreide seg om, var fokuset ensidig rettet mot seksualitet og kjønn. Amina anså skam og ære som konsekvent relatert til kjønn. Dette som et apropos til den sosialantropologiske debatten om hvorvidt kvinnen ifølge visse æreskodekser kan opparbeide ære på egenhånd:

Ære forbindes med mann og skam med kvinnen. Foreldrene mine sier: "Har du ingen skam?" til meg, mens de sier: "Har du ingen ære?" til brødrene mine. Dette går igjen. Mannens ære er avhengig av kvinnen. Kvinnen har mye å si i forhold til ære og skam i det pakistanske miljøet. (Amina, 23, pakistansk bakgrunn).

Jasmin hadde tilsvarende tanker om kvinner som et uttrykk for kollektivets ære. Dette var noe hun - mot sin vilje - var påvirket av:

Jenter er familiens ære. Jenter er mer sårbare. Sånn forskjell er det $\mathrm{i}$ alle religioner og kulturer. Bør det være sånn? Nei, men det er sånn. Og jeg er sånn selv. Jeg reagerer mer på en jente. Det er sånn samfunnet er. Jeg vil helst ikke mene det, men det bare blir sånn. Hvis en jente har vært borti 10 gutter syns jeg det er verre enn at en gutt har vært borti 10 jenter. (Jasmin, 26, pakistansk bakgrunn).

Den 29 år gamle Abdullah kom fra Saudi-Arabia til Norge som ung voksen. Han sto for en lignende tankegang: “Kona mi er min ære, moren min er min ære, søsteren min er min ære. Det går mest på kvinner". Den ovenfor nevnte Zahra, var enig i at ære var knyttet til kvinner og seksualitet. Det gjentok hun flere ganger i intervjuet. Dette ble ansett å være en del av islam:

Sharaf betyr veldig mye. For det første tenker jeg på en jente. Er hun sharifi, det vil si har hun en ren ære? I så fall er hun en jomfru. Når noen kommer på besøk, spør de gjerne om hvilken sharaf jenta har. Om æren er bra, så er jenta bra, om æren er dårlig 
så er jenta dårlig. (...) Det er mye i den gamle generasjonen som er veldig viktig. En jente uten ære er ikke verdt noe. (...) Det viktigste i islam for en jente er jomfrudommen hennes. Hun skal være jomfru fram til hun gifter seg. (Zahra, 18, shiamuslim med irakisk bakgrunn).

Samtidig ga Zahra et annet sted i intervjuet uttrykk for at ifølge islam var det like viktig for en gutt som for en jente å være jomfru. Dette illustrerer at også hun ga uttrykk for en viss spenning mellom idealet innen normativ religiøsitet og vanlige holdninger innen enkelte muslimske samfunn.

\section{Generasjons-forskjeller}

Hovedtyngden av respondentene beskrev spenninger generasjonene imellom i synet på ærestenkningen. De mente den eldre generasjonen var preget av holdningene fra hjemlandet. Selv mente de seg å ha et syn på rykter, ære og skam som klart atskilte seg fra foreldrenes. Det kunne også føre til visse motsetninger. For å sitere fire forskjellige respondenter:

Første generasjonen tenker mere på skam og ære og hva alle andre vil si. (...) Her er jeg veldig forskjellig fra mine egne foreldre. (...) En dag må det bli slutt med de greiene der - det presset fra det pakistanske miljøet. Jeg er veldig glad i foreldrene mine, og jeg er redd for at de skal dø en dag av ryktene. Men jeg håper de er så pass sterke at de kan gi faen i hva alle andre tenker (Fatema, 30, pakistansk bakgrunn).

Foreldregenerasjonen av pakistanere er veldig opptatt av status. Ha en datter som er lege. (...) De første årene skjulte jeg at jeg begynte på legestudiet - ville bli behandlet som meg selv og ikke som en tittel (Aima, 22, pakistansk bakgrunn).

Det er de gamle som snakker mest om det (rykte og ære). De unge vil leve akkurat slik de ønsker, men de er veldig forsiktig de og, for de er redd for å gjøre noe dumt (Rana, 24, afghansk bakgrunn).

Det er mange pakistanske jenter som går med slike heldekkende klær fordi foreldrene mener det er riktig. Om det er på grunn av religion eller tradisjon vet jeg ikke, men hvis ikke de gjør det, (...) mister de sin izzat. Men jeg mener det er litt feil - Herre Gud! (Amina, 23, pakistansk bakgrunn).

Flere opplevde det sosiale presset plagsomt:

Det blir et press på ungdommene: Hvorfor går du ikke i moskeen, når alle andre gjør det? (...) Hvis du melder deg ut av det pakistanske miljøet og vil fortrekke norske venner, så får du høre: "Hun der er så norsk av seg". Eller hvis du drikker alkohol og går ut på byen, får du et stempel på deg - et negativt stempel. Det går negative rykter om deg. (...) Her i Oslo er islam så mye sterkere. Alle passer på hverandre. I Stavanger kan man mer være seg selv. Her må du bli som de andre. (Jasmin, 26, pakistansk bakgrunn).

Zahra som klart sluttet seg til tradisjonell æresoppfatning, ville naturlig nok slutte seg til verdiene til den eldre generasjonen på dette området:

Selv om ære betyr mye mer for meg, (...). Det gjør det for den gamle generasjonen også. Det er mye i den gamle generasjonen som er veldig viktig. En jente uten ære er ikke verdt noe. (Zahra, 18, shiamuslim, iraksisk bakgrunn). 
Flere mente den eldre generasjonen tok med seg holdninger som var vanlige i hjemlandet da de emigrerte, uten å følge med utviklingen hjemme. Moderniseringen i hjemlandet - også i forhold til skam og ære - har ikke nådd fram til de etniske miljøene i Norge. Utsagn fra tre forskjellige respondenter kan illustrere dette:

Pakistanere i Norge lever nærmest på 70- og 80-tallet i forhold til Pakistan som har blitt mer moderne. Foreldrene mine kom på 70-tallet. De sier at i Pakistan er det sånn og sånn. Når du reiser til Pakistan, så ser du at det har blitt veldig moderne. (Jasmin, 26, pakistansk bakgrunn).

I storbyer i Pakistan er folk mer liberale enn folk er her nå. Fordi folka som bor her i Norge, de tenker fortsatt som i Pakistan som for 20 år siden.( ...) Pakistan har jo blitt veldig modernisert. (Amina, 23, pakistansk bakgrunn).

Utviklingen skjer hurtigere i Tyrkia enn i Norge, men de som kom til Norge, er i et lite samfunn. De kom fra landsbyer og lever opp til den gamle kulturen. Tyrkerne i Tyrkia er mere moderne enn tyrkerne i Norge. (Ayse, 28, tyrkisk bakgrunn).

I tillegg er de etniske miljøene relativt små og oversiktlige, noe som gjør at den sosiale kontrollen blir sterkere. Fire respondenter med henholdsvis tyrkisk og pakistansk bakgrunn beskrev det slik:

Jeg: Er det noen forskjell på skam og ære for tyrkere i Norge og Tyrkia?

Ayse: Siden vi er en liten gruppe her, må man være mere forsiktig. Her er det mer kontroll. Folk kan snakke om hverandre. Hvis du gjør noe, så kommer andre og snakker om det. Da kan det være rykter, da kan det være baksnakking (...) Hvis det er noe skam, kan den personen føle seg veldig dårlig. Da må man være forsiktig hva man gjør og hva man ikke gjør.

Jeg: Må man være mer forsiktig i Oslo enn i Izmir fordi det er et mindre tyrkisk miljø her?

Ayse: Ja, slik er det. Det er mere kontroll, folk er opptatt med hverandre hele tiden. Men det er ikke sånn i Izmir. Alle lever sitt eget liv. Men reglene er de samme - de islamske reglene (...) Men her er det slik at hvis du bryter noen regler, da begynner folk å snakke om deg. (Ayse, 28, tyrkisk bakgrunn).

Den pakistanske befolkningen her er som et tettbygd strøk og hvis noen ser meg for eksempel med kjæresten ute, vil det begynne å gå rykter, ikke sant? Selv om foreldrene mine vet jeg har kjæreste, (...) men det at andre begynner å snakke, det vil på en måte påvirke dems izzat da (...) Pga denne snakkinga hit og dit. (Amina, 23, pakistansk bakgrunn).

Jeg tror det er sterkere sosial kontroll (blant pakistanere) i Norge enn hva det er der nede, selv om alt skjer der også. (...) Man bruker skam og ære for å holde kontroll på ungene. (...) Foreldrene sier til ungene sine: Hvis du gjør det og det, er det skam for oss - det går ut over izzat'en vår. (Usman, 19, pakistansk bakgrunn).

Jeg drikker, jeg røyker, men jeg gjør ikke det på Grønland. (...) Jeg røyker aldri åpent. I London er det ingen som kjenner meg igjen, så der driter jeg i det. Jeg vil ikke at noen skal si: Jeg så dattera di stå på Grønland og røyke. Jeg kan røyke hvor jeg vil, men jeg tar hensyn til dem (foreldrene). Jeg vet søstera mi gir veldig mye informasjon til mamma. (Fatema, 30, pakistansk bakgrunn). 
Sterk sosial kontroll og tradisjonelle synspunkter på ære og kjønn blir her beskrevet som fortsatt eksisterende i norske muslimske miljøer (Fursseth 2008). Samtidig signaliserer de unges holdninger at endringer er på vei på disse områdene. Mirdals undersøkelse blant tyrkisk-danske kvinner viste at innholdet i hva som ga ære endret seg radikalt i løpet av 20 år, mens selve vektleggingen av ære fortsatt sto sterkt (Mirdal 1984; Mirdal 2006; Mirdal \& Farimagsgade 2000). Dette var endringer som skjedde hos den enkelte. Den herværende empirien tyder på at hvis man så går til neste generasjonen, er det ikke bare innholdet som endres, men selve æresbegrepets funksjon og stilling. Unge norske muslimer ønsker ikke lenger at hensynet til hva andre måtte tenke og mene om dem, skal være styrende for deres atferd. Dette innebærer en langt mer grunnleggende endring enn den Mirdal beskrev hos samme individer over tid. I tillegg oppviser mange innen andre generasjons muslimer i Norge en radikalt annerledes og dypere refleksjon omkring emnet, samt bevissthet om og innsikt i selve endringsprosessen. Denne endringsprosessen synes å være preget av avtradisjonalisering og individualisering i tråd med analysene hos Heelas og Schiffauer (Heelaset al.,. 1996; Schiffauer 1988).

Flertallet av respondentene understreket at de tok avstand fra æreskulturen i foreldrenes hjemland, samtidig med at de ga uttrykk for relativt positive vurderinger av norsk kultur angående dette. På den måten indikerte de at migrasjonen i det minste kunne være én av årsaksfaktorene til endringen. En annen årsak, var at de mente seg å ha større kunnskap om rett tolkning av islam i dette spørsmålet, enn det folk flest har i foreldrenes hjemland. Også dette kan indirekte knyttes til migrasjon. Ingen av respondentene oppga opprør mot foreldrene som en selvstendig årsak bak endringen.

Dodd nevnte tre årsaksforklaringer til endringer i ærestenking: urbanisering, utdannelse og politiske revolusjoner med medførende ideologiendring (Dodd 1973, 46-53). Hvis man bytter ut revolusjon med emigrasjon, kan disse momentene fortsatt gjelde som årsaksforklaring til endring i holdningene fra foreldregenerasjonen til ungdomsgenerasjonen av norske muslimer - slik de selv beskriver dem.

\section{Avsluttende bemerkninger}

Om lag 19 av de 24 respondentene tok avstand fra det de oppfattet som et tradisjonelt æresbegrep slik det er beskrevet innen type A. Kun én respondent sluttet seg til hver av typene $B$ og $C$ og rundt regnet fire stod nærmest type D som forsvarte en tradisjonell æresforståelse.

En kvalitativ undersøkelse har liten statistisk verdi. Den skjeve prosentvise fordelingen er likevel så påfallende, at en avstandstaken til tradisjonell æresforståelse trolig har stor oppslutning blant unge norske muslimer generelt. Dessuten er andre generasjons utsagn om forskjellen i forhold til egne foreldre en sterk indikasjon på at de som har vokst opp i Norge, i stor grad har en annerledes måte å bedømme det tradisjonelle æresbegrepet på - samt religionens forhold til dette begrepet - enn de som hadde sin barndom i et muslimsk samfunn. 
Samtlige respondenter i undersøkelsen var enige om at ærestenkning er et fenomen som står sterkt innen tradisjonelle muslimske samfunn. Utsagnene om foreldrenes kulturbakgrunn var i så måte til dels sterke, og lang mer essensialistiske enn det som er vanlig i dagens sosialantropologiske litteratur. Den store majoriteten som resonnerte i tråd med typene $\mathrm{A}$ og $\mathrm{B}$, tok avstand fra tradisjonell æresoppfatning til dels med sterkt emosjonelt engasjement. Avstandstakingen hvilte på teoretisk refleksjon og egne erfaringer. Samtidig ble islamsk religion brukt som argument mot ærestenkingen slik de mente den kommer til uttrykk i muslimske samfunn. De islamske verdiene i dette spørsmålet ble ansett å være mer til stede i det norske samfunnet enn de tradisjonelt muslimske. Det vil si at mange brukte religionen islam som begrunnelsen for verdier som de i dette spørsmålet mente lå nær rådende verdier i det norske samfunnet. Flertallet sto for en vurdering av ære, skyld og skam som på flere punkter lå nær den rådende betraktningsmåten innen dagens psykologi. Innen type A dreier likevel skylden seg mer dreier om brudd på teistisk åpenbarte regler, enn om mellommenneskelig empatimotivert skyld.

Et mindretall av respondentene sto for en mer positiv vurdering av ærestenkningen og begrunnet den ut fra islam som normativ religion. Et av argumentene var at hensynet til ære og rykte fungerer som en moralsk motivasjonsfaktor og at frykten for skam virker preventivt mot negative handlinger.

Ut fra Paul Heelas forståelse er holdningen blant flertallet av respondentene, et tydelig eksempel på det han kaller avtradisjonalisering (Heelaset al.,. 1996, 2, 7-8, 212; Lien 2002, 22). I henhold til Peter Bergers terminologi representerer endringen en bevegelse fra honor til dignity (Aase 2002, 1-2; Bergeret al.,. 1974, 84; Lien 1993, 260-261; Lien 2002, 21-25). Samtidig kan denne endringen representere en bevegelse bort fra vektlegging av det ytre og kollektive henimot det indre og individuelle (Riesmanet al.,. 1950; Schiffauer 1988). Direkte og indirekte indikerte flertallet av respondentene at migrasjon kunne være en viktig årsaksfaktor bak denne endringsprosessen preget av avtradisjonalisering og individualisering.

\section{LITTERATUR}

Aase, Tor

2002 Tournaments of Power: Honor and Revenge in the Contemporary World, Ashgate Pub Limited.

Abraham, Margaret

2000 Speaking in the Unspeakable: Marital Violence Among South Asian Immigrants in the United States, Rutgers University Press.

Abu-Rabia, Aref

2011 “Family Honor Killings: Between Custom and State Law", The Open Psychology Journal 4, 34-44.

Adamska-Salaciak, Arleta

2012 Dictionary Definitions: Problems and Solutions, Adam Mickiewicz University.

Akpinar, Aylin

2003 "The Honour/Shame Complex Revisited: Violence against Women in the Migration Context". Women's studies international forum 26, 425-442.

Al-Krenawi, Alean, Vered Slonim-Nevo, Yaniv Maymon, \& Salem Al-Krenawi

2001 "Psychological responses to blood vengeance among Arab adolescents", Child abuse E neglect 25 (4), 457-472. 
Albera, Dionigi

2006 "Anthropology of the Mediterranean: Between crisis and renewal", History and Anthropology 17 (2), 109-133.

Ali, Rabia

2001 The Dark Side of 'Honour': Women Victims in Pakistan, Shirkat Gah.

Alshawi, Hiyan

1987 "Processing dictionary definitions with phrasal pattern hierarchies", Computational Linguistics 13 (3-4), 195-202.

Barrett, Karen Kaplovitz

1995 "A Functionalist Approach to Shame and Guilt”, In: June Price Tangney \& Kurt W. Fischer, eds., Self-Conscious Emotions. The Psychology of Shame, Guilt, Embarrassment, and Pride, The Guiltford Press.

Basri, Muhammad Hassan

2010 Andai Surga \& Neraka Tidak Ada (Hvis himmel og helvete ikke fantes), Millenia.

Baumeister, Roy F., Arlene M. Stillwell, \& Todd F Heatherton

1995 "Interpersonal Aspects of Guilt: Evidence from Narrative Studies", in: June Price Tangney \& Kurt W. Fischer, eds., Self-Conscious Emotions. The Psychology of Shame, Guilt, Embarrassment, and Pride, The Guiltford Press.

Baxter, Diane

2007 "Honor thy sister: Selfhood, gender, and agency in Palestinian culture", Anthropological quarterly 80 (3), 737-775

Benedict, Ruth

1946 The Chrysanthemum and the Sword: Patterns of Japanese Culture, Houghton Mifflin.

Berger, Peter L., Brigitte Berger, \& Hansfried Kellner

1974 The Homeless Mind: Modernization and Consciousness, Random House.

Bertens, $\mathrm{K}$.

2002 Etika, Kompas Gramedia.

Bourdieu, Pierre

1966 "The Sentiment of Honour in Kabyle Society", In: J.G. Peristiany, ed., Honour and Shame: The Value of Medditerranean Society, The University of Chicago Press.

Bryant, Antony, \& Kathy Charmaz

2007 The SAGE Handbook of Grounded Theory, SAGE Publications.

Casimir, Michael J, \& Susanne Jung

2009 "'Honor and Dishonor': Connotations of a Socio-symbolic Category in Cross-Cultural Perspective", Emotions as Bio-cultural Processes, 229-280.

Charmaz, Kathy

2003 "Grounded Theory", Strategies of qualitative inquiry 2, 249.

2006 Constructing Grounded Theory: A practical Guide through Qualitative Analysis, SAGE Publications.

Cohen, Taya R, AT Panter, \& Nazli Turan

2012 "Guilt Proneness and Moral Character", Current Directions in Psychological Science 21 (5), 355359.

de Pina-Cabral, Joao

1989 "The Mediterranean as a category of regional comparison: A critical view", Current Anthropology 30 (3), 399-406.

Dodd, Peter C

1973 "Family honor and the forces of change in Arab society", International Journal of Middle East Studies 4 (1), 40-54.

Fischer, Kurt W., \& June Price Tangney

1995 "Self-Conscious Emotions and the Affect revolution: Framework and Overview", In: June Price 
Tangney \& Kurt W. Fischer, eds., Self-conscious emotions: the psychology of shame, guilt, embarrassment, and pride, Guilford Press.

Furseth, Inger

2008 "Social Capital and Immigrant Religion", Nordic Journal of Religion and Siociety 21 (2), 147-164.

Gerring, John

1999 "What makes a concept good? A criterial framework for understanding concept formation in the social sciences", Polity, 357-393.

Gill, Aisha

2006 "Patriarchal violence in the name of 'honour", International Journal of Criminal Justice Sciences 1 (1), 1-12.

Ginat, Joseph

1982 Women in Muslim rural Society: Status and Role in Family and Community, Transaction Books.

Guerra, Valeschka Martins, Roger Giner-Sorolla, \& Milica Vasiljevic

2013 "The importance of honor concerns across eight countries", Group Processes E Intergroup Relations 16 (3), 298-318.

Hamady, Sania

1960 Temperament and Character of the Arabs, Twyane Publishers.

Harpel, Whittaker Wigner

2010 Conceptions of Masculinity Among Arab Americans, Washington State University.

Heelas, Paul, Scott Lash, \& Paul Morris

1996 Detraditionalization: Critical reflections on authority and identity, Blackwell.

Herzfeld, Michael

1980 "Honor and shame: Problems in the comparative analysis of moral systems", Man 15, 339-51.

2005 "Practical Mediterraneanism: excuses for everything, from epistemology to eating", Rethinking the Mediterranean, 45-63.

Hoffman, Martin L.

2000 Empathy and Moral Development: Implications for Caring and Justice, Cambridge University Press.

Horden, Peregrine, \& Nicholas Purcell

2000 The corrupting sea: A study of Mediterranean history. Volume 1, Blackwell.

2006 "The Mediterranean and "the New Thalassology"“, The American Historical Review 111 (3), $722-$ 740 .

Ijzerman, Hans, \& Dov Cohen

2011 "Grounding cultural syndromes: Body comportment and values in honor and dignity cultures", European Journal of Social Psychology 41 (4), 456-467.

Joireman, Jeff

2004 "Empathy and the self-absorption paradox II: Self-rumination and self-reflection as mediators between shame, guilt, and empathy", Self and Identity 3 (3), 225-238.

Kaufman, Gershen

1996 The Psychology of Shame: Theory and Treatment of Shame-based Syndromes, Springer.

Ketelaar, Timothy, \& Wing Tung Au

2003 "The effects of feelings of guilt on the behaviour of uncooperative individuals in repeated social bargaining games: An affect-as-information interpretation of the role of emotion in social interaction", Cognition E Emotion 17 (3), 429-453.

Khader, Naser

1996 Ære og skam: Det islamiske familie- og livsmønster - fra undfangelse til grav, Borgen.

Kirti, Anand, Prateek Kumar, \& Rachana Yadav

2011 "The Face of Honour Based Crimes: Global Concerns and Solutions", International Journal of Criminal Justice Sciences 6 (1-2), 343-357. 
Krogseth, Otto

2009 "Religion og kultur. Forsøk på en forhåndsbestemmelse" in: Arve Brunvoll, Hans Bringeland, Nils Gilje \& Gunnar Skirbekk, eds., Religion og kultur. En flerfaglig samtale, Universitetsforlaget.

Lewis, Helen Block

1971 Shame and Guilt in Neurosis, International Universities Press.

Lien, Inger-Lise

1993 Moral og emosjoner i pakistansk Punjab, Institutt og museum for antropologi, Universitetet i Oslo.

2002 "The Dynamics of Honor in Violence and Cultural Change. A case from an Oslo inner city district", in: Tor Aase, ed., Tournaments of Power, Ashgate.

Lutwak, Nita, Jacqueline B Panish, Joseph R Ferrari, \& Brian E Razzino

2001 "Shame and guilt and their relationship to positive expectations and anger expressiveness", Adolescence 36 (144), 641,653.

Luyten, Patrick, Johnny RJ Fontaine, \& Jozef Corveleyn

2002 "Does the Test of Self-Conscious Affect (TOSCA) measure maladaptive aspects of guilt and adaptive aspects of shame? An empirical investigation", Personality and Individual Differences 33 (8), 1373-1387.

MacDonald, James

1998 "Disclosing Shame" in: Paul Gilbert \& Bernice Andrews, eds., Shame. Interpersonal Behavior, Psychopatologi, and Culture, Oxford University Press.

Mahfuzh, Najlah

2013 La Tahzan for Girls. Agar Kamu Para Gadis Tidak Galau Hadapi Masa Depan (Jenter trenger ikke være lei seg. For deg unge jente, så du ikke blir forvirret i møte med fremtiden), Mirqat Publishing.

Meetoo, Veena, \& Heidi Safia Mirza

2007 "“There is nothing 'honourable'about honour killings": Gender, violence and the limits of multiculturalism". Women's Studies International Forum 30, 187-200.

Mills, Jane

2006 "Adopting a Constructivist Approach to Grounded Theory : Implications for Research Design", International Journal of Nursing Practice 12 (1), 8.

Mills, Jane, Ann Bonner, \& Karen Francis

2008 "The Development of Constructivist Grounded Theory", International Journal of Qualitative Methods 5 (1), 25-35.

Mirdal, Gretty M.

1984 "Stress and distress in migration: Problems and resources of Turkish women in Denmark", International Migration Review, 984-1003.

2006 "Stress and Distress in Migration: Twenty Years After", International Migration Review 40 (2), 375-389.

Mirdal, Gretty M, \& Øster Farimagsgade

2000 "Changing idioms of shame: Expressions of disgrace and dishonour in the narratives of Turkish women living in Denmark", International Journal of Psychology 12 (4), 395-414.

Mosquera, Patricia M Rodriguez, Antony SR Manstead, \& Agneta H Fischer

2002 "The role of honour concerns in emotional reactions to offences", Cognition \& Emotion 16 (1), 143-163.

Noland, James RL

2010 "Freeing Anthropology from Critique", Imagination and Critique, 119-138.

Nordin, Magdalena

2004 "Religiøsitet blant migranter", Lund Studies in Sociologi of Religion 3.

Page, Sarah-Jane, \& Andrew Kam-Tuck Yip

2012 "Hindu, Muslim and Sikh Young Adults: Gendered Practices in the Negotiation of Sexuality and Relationship", in: Peter Nynäs \& Andrew Kam-Tuck Yip, eds., Religion, gender and sexuality in everyday life, Ashgate, 51-69. 
Pap, Arthur

1964 “Theory of definition", Philosophy of science 31 (1), 49-54.

Parla, Ayse

2009 "Remembering across the border: postsocialist nostalgia among Turkish immigrants from Bulgaria", American ethnologist 36 (4), 750-767.

Passaro, Joanne

1997 "You can't take the subway to the field!:'Village'epistemologies in the global village", Anthropological locations: Boundaries and grounds of a field science, 147-162.

Pely, Doron

2011 "Where East not always meets West: Comparing the Sulha process to Western-style mediation and arbitration", Conflict resolution quarterly 28 (4), 427-440.

Peristiany, J. G.

1966 Honour and Shame: the Value of Medditerranean Society, The University of Chicago Press.

Rasmi, Sarah

2012 Perceived Dyadic Cultural Discrepancies, Intergenerational Conflict, and Ethnocultural Identity Conflict in Arab Canadian Families, Ph.d.-afhandling, The University of Guelph, Ontario, Canada.

Repstad, Pål

2007 Mellom nærhet og distanse : kvalitative metoder i samfunnsfag (Between proximity and distance. Qualitative methods in social science), Universitetsforlaget.

Rey, Alain

2000 "Defining definition", in: Juan C. Sager \& Alain Rey, eds., Essays on Definition, John Benjamins Publishing.

Riesman, David, Nathan Glazer, \& Reuel Denney

1950 The Lonely Crowd: A Study of the Changing American Character, Yale University Press.

Riessman, Catherine Kohler

2009 "Considering Grounded Theory: Categories, Cases, and Control", in: Charmaz. Kathy, ed., Constructing Grounded Theory: A Practical Guide, Sage.

Robinson, Richard

1972 Definition, Clarendon Press.

Scheff, Thomas J.

1988 "Shame and conformity: The deference - emotion system", American Sociological Review 53 (3), 395-406.

1995 "Conflict in the family Systems: The Role of Shame", in: June Price Tangney \& Kurt W. Fischer, eds., Self-conscious emotions: the psychology of shame, guilt, embarrassment, and pride, Guilford Press.

Schiffauer, Werner

1988 "Migration and Religiousness", in: Thomas Gerholm \& Yngve Georg Lithman, eds., The New Islamic Presence in Western Europe, Mansell Publishing.

Sev'er, Aysan, \& Gökçeçiçek Yurdakul

2001 "Culture of Honor, Culture of Change: A Feminist Analysis of Honor Killings in Rural Turkey", Violence Against Women 7.

Silfver, Mia, \& Klaus Helkama

2007 "Empathy, guilt, and gender: A comparison of two measures of guilt", Scandinavian journal of psychology 48 (3), 239-246.

Tangney, June Price, \& Ronda L. Dearing

2002 Shame and Guilt, Guildford.

Tangney, June Price, Rowland S. Miller, Laura Flicker, \& Deborah Hill-Barlow

1996 "Are shame, Guilt , and Embarrassment distinct Emotions?", Journal of Personality and Social Psychology 70 (6), 1256. 
Tangney, June Price, Jeff Stuewig, \& Debra J Mashek

2007 "Moral Emotions and Moral Behavior", Annual Review of Psychology 58, 345.

Tangney, June Price, Jeffrey Stuewig, Debra Mashek, \& Mark Hastings

2011 “Assessing Jail Inmates' Proneness To Shame and Guilt Feeling Bad About the Behavior or the Self?", Criminal justice and behavior 38 (7), 710-734.

Thorbjørnsrud, Berit

2002 "Ære og skam i et antropologisk perspektiv", Idehistorisk tidsskrift 3.

2003 “En skråsikker bok om ære", Nytt Norsk Tidsskrift 2, 231-237.

Thornberg, $\mathrm{R}$.

2012 "Informed Grounded Theory", Scandinavian Journal of Educational Research 56 (3), 243-259.

Thornberg, Robert, \& Kathy Charmaz

2013 "Grounded Theory and Theoritical Coding", The SAGE handbook of qualitative data analysis, SAGE.

Weidman, Amanda J

2003 "Beyond honor and shame: Performing gender in the Mediterranean", Anthropological quarterly 76 (3), 519-530.

Werbner, Pnina

2005 "Honor, shame and the politics of sexual embodiment among South Asian Muslims in Britain and beyond: An analysis of debates in the public sphere", International Social Science Review 6 (1), 25-47.

Wikan, Unni

1984 "Shame and Honour: A Contestable Pair", Man 19 (4).

2005 For ærens skyld: Fadime til ettertanke, Universitetsforlaget.

Wurmster, Léon

1987 "Shame: The Veiled Companion of Narcissim" in: Donald A. Nathanson, ed., The many faces of shame, Guilford Press.

Zahn-Waxler, Carolyn, \& Joann Robinson

1995 "Empaty and Guilt: Early Origins of Feelings of Responsibility", in: June Price Tangney \& Kurt W. Fischer, eds., Self-Conscious Emotions: The Psychology of Shame, Guilt, Embarrassment, and Pride. Guilford Press.

Levi Geir Eidhamar, dosent, ph.d., Institut for Religion, Filosofi og Historie, Universitetet i Agder levi.g.eidhamar@uia.no 